\title{
The availability of novelty sweets within high school localities
}

\author{
A. Aljawad, ${ }^{* 1}$ M. Z. Morgan, ${ }^{2}$ J. S. Rees ${ }^{3}$ and R. Fairchild ${ }^{4}$
}
IN BRIEF
- Highlights the growth in the novelty sweets market.
- These sweets are acidic and sweet and therefore can lead to both dental caries and dental erosion.
- The high sugar content may also contribute to overnutrition and overweight or obesity.
- The design of these sweets, in resealable containers, encourages repeated consumption which is detrimental to oral health.

\begin{abstract}
Background Reducing sugar consumption is a primary focus of current global public health policy. Achieving 5\% of total energy from free sugars will be difficult acknowledging the concentration of free sugars in sugar sweetened beverages, confectionery and as hidden sugars in many savoury items. The expansion of the novelty sweet market in the UK has significant implications for children and young adults as they contribute to dental caries, dental erosion and obesity. Objective To identify the most available types of novelty sweets within the high school fringe in Cardiff, UK and to assess their price range and where and how they were displayed in shops. Subjects and methods Shops within a ten minute walking distance around five purposively selected high schools in the Cardiff aea representing different levels of deprivation were visited. Shops in Cardiff city centre and three supermarkets were also visited to identify the most commonly available novelty sweets. Results The ten most popular novelty sweets identified in these scoping visits were (in descending order): Brain Licker, Push Pop, Juicy Drop, Lickedy Lips, Big Baby Pop, Vimto candy spray, Toxic Waste, Tango candy spray, Brain Blasterz Bitz and Mega Mouth candy spray. Novelty sweets were located on low shelves which were accessible to all age-groups in 73\% (14 out of 19) of the shops. Novelty sweets were displayed in the checkout area in 37\% (seven out of 19) shops. The price of the top ten novelty sweets ranged from $39 p$ to 11 . Conclusion A wide range of acidic and sugary novelty sweets were easily accessible and priced within pocket money range. Those personnel involved in delivering dental and wider health education or health promotion need to be aware of recent developments in children's confectionery. The potential effects of these novelty sweets on both general and dental health require further investigation.
\end{abstract}

\section{INTRODUCTION}

Dental caries, dental erosion and obesity are non-communicable diseases common in UK children. ${ }^{1-3}$ Research has established that diet is one of the major aetiological factors in the development of dental caries, dental erosion $^{4-8}$ and obesity among children. ${ }^{9-11}$

There is a particularly strong relationship between eating foods high in 'free' sugars and dental caries ${ }^{7,12,13}$ The term free sugars refers to all mono and disaccharides added to foods by the manufacturer, cook or

${ }^{1}$ Clinical Research Student; ${ }^{2}$ Senior lecturer in dental public health, Applied Clinical Research and Public Health, College of Biomedical and Life Sciences, Cardiff University, School of Dentistry; ${ }^{3}$ Senior Lecturer in Nutrition, Cardiff Metropolitan University, Cardiff; ${ }^{4}$ Professor of Restorative Dentistry, Cardiff University School of Dentistry, Cardiff

*Correspondence to: Mr Ayman Al Jawad, sponsored by $\mathrm{MOHE}$, Kingdom of Saudi Arabia

Email:aljawadaa@cardiff.ac.uk

\section{Refereed Paper}

Accepted 12 April 2016

DOI: $10.1038 /$ sj.bdj.2016.412

${ }^{\circ}$ British Dental Journal 2016; 220: 575-579 consumer, plus sugars naturally present in honey, fruit juices and syrups. ${ }^{14}$

Reducing sugar consumption to $5 \%$ of total energy from free sugars is a primary focus of current global public health policy. ${ }^{14,15}$ Achieving this goal will be difficult acknowledging the concentration of free sugars in children's diets. It has been estimated that sugars, preserves and confectionery contribute $21 \%$ free sugars to the total energy of 11-18-year-olds in the UK, with $5 \%$ being attributed specifically to sugar confectionery. ${ }^{16}$

In the UK decennial surveys of children's teeth have been carried out since $1973 .{ }^{2}$ Encouragingly, since 1983 there has been a downward trend in dental caries experience among all age-groups taking part. However, the prevalence remains high for this largely preventable disease. In 2013, nearly a half $(46 \%)$ of 15 -year-olds and a third (34\%) of 12-year-olds had 'obvious decay experience' in their permanent teeth. Worryingly, there are wide inequalities in experience, with all age groups eligible for free school meals (that is, lower income families) having greater experience of dental caries. ${ }^{2}$

Epidemiological studies have highlighted that frequent consumption of acidic foods and/or drinks can lead to the development of dental erosion. ${ }^{8,17}$ Many of these acidic products contain high levels of free sugars which also contribute to the development of dental caries. ${ }^{18}$

The development of tooth surface loss (TSL) at an early age in the deciduous and the mixed dentition is becoming an increasing concern for the dental profession with erosion being the primary cause. The most recent National Child Dental Health Survey reported an increase TSL for all age-groups taking part between 2003 and 2013. For example, in 12-year-olds TSL in incisors increased from $12 \%$ to $24 \%$ and from $30 \%$ to $38 \%$ in buccal and lingual surfaces respectively; the increase in molar teeth was from $19 \%$ to $25 \%{ }^{2}$

Recent systematic reviews have documented that the consumption of foods high in free sugars can lead to an increase in 


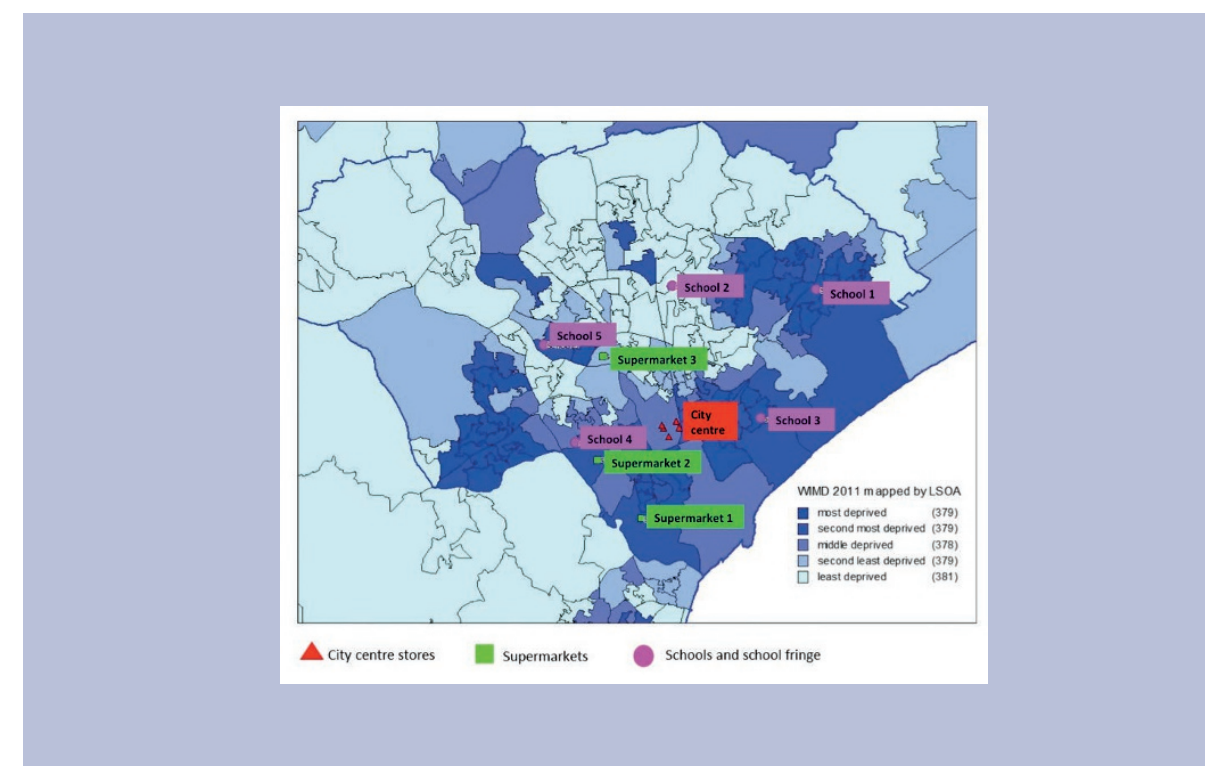

Fig. 1 Reference locations (five schools, five city centre stores and three supermarkets) Cardiff Unitary Authority, by quintiles of deprivation, WIMD 2011

Table 1 Summary of types and price range of novelty sweets in shops within school fringes

\begin{tabular}{l|l|l|l|l|l} 
SETTING & $\begin{array}{l}\text { WIMD (2011) deprivation quintile } \\
\text { for school location }\end{array}$ & $\begin{array}{l}\text { No. of } \\
\text { visited } \\
\text { shops }\end{array}$ & $\begin{array}{l}\text { No. of } \\
\text { shops sell- } \\
\text { ing sweets }\end{array}$ & $\begin{array}{l}\text { Types of } \\
\text { Novelty } \\
\text { sweets }\end{array}$ & $\begin{array}{l}\text { Price } \\
\text { range } \mathrm{f}\end{array}$ \\
\hline School 1 & Second most deprived & 12 & 4 & 15 & $0.10-1.49$ \\
\hline School 2 & Least deprived & 11 & 0 & None & - \\
\hline School 3 & Most deprived & 10 & 5 & 16 & $0.39-1.00$ \\
\hline School 4 & Middle deprived & 12 & 4 & 11 & $0.39-0.99$ \\
\hline School 5 & On border with second least deprived & 10 & 0 & None & - \\
\hline City centre & - & 10 & 5 & 17 & $0.39-0.99$ \\
\hline 3 supermarkets & - & 3 & 1 & 5 & $0.39-2.99$ \\
\hline
\end{tabular}

overweight and obesity. ${ }^{9,19}$ According to the 2011 Health Surveys for England, Scotland and Wales, the percentage of children aged 2-15 years who were obese was 5.5\% for boys and $7.2 \%$ for girls. Furthermore, the percentages for children either obese or overweight were $22 \%$ and $28 \%$ for boys and girls respectively. ${ }^{3}$

Over the last decade sour and novelty sweets have continued to gain popularity in the UK. ${ }^{20}$ Novelty sweets are characterised by being resealable, both sweet and sour tasting, are usually brightly coloured, resemble or can be used as toys and are sold at pocket money prices. ${ }^{21}$ The marketing of novelty sweets is mainly directed towards children who are the primary consumers of confectionery in the UK. ${ }^{18} \mathrm{~A}$ focus group study of novelty sweets highlighted that 9-10-yearolds thought novelty sweets were aimed at children older than themselves. ${ }^{21}$ This older age group also have more spending power according to pocket money surveys. ${ }^{22}$ Sour sweets were first introduced in the late 1970s by adding a sour flavoured coating which contained a mixture of simple organic acids such as citric, malic and tartaric, to the surface of the sweet. Sour sweets, incorporating novelty sweets, a more recent development, have grown in market share and social acceptability. For example in the UK, in 2015 Haribo was the leading social brand food company according to their Fast Moving Consumer Goods ranking. ${ }^{23}$

Novelty sweets are of particular concern because they contain both high levels of free sugars and acids. Furthermore, their product design facilitates regular frequency of consumption (many are resealable). Consequently, they have the potential to cause dental caries and dental erosion and for children to consume extra 'empty calories' which could lead to the development of overweight or obesity. It is because of these concerns relating to oral and general health that it is important to address free sugars, including confectionery consumption, as a part of an overall health promotion programme. ${ }^{1,15}$
To date, studies on the health implications of novelty sweets are limited, addressing only the $\mathrm{pH}$, neutralisable acidity and enamel loss associated with their consumption $^{24-26}$ and their general availability to children. $^{22}$ The objective of this study was to build on existing research by identifying the most available types of novelty sweets, assess their price range and where and how they were displayed in shops.

\section{MATERIALS AND METHODS}

Scoping visits were undertaken to determine the varieties of novelty sweets available within the high school fringe ${ }^{29}$ of selected schools in Cardiff, UK. A list of the most available novelty sweets was created by visiting purposively selected city centre stores (non-limited to sweet shops; it is known that some fashion stores stock sweets), shops located near five high schools and three supermarkets from the wider Cardiff conurbation (Fig. 1).

High schools (children aged 11-18 years) were purposively selected to represent a cross-section of the socio-economic characteristics of the city using the Welsh Index of Multiple Deprivation ${ }^{28}$ to inform this process. Five high schools were selected, one in each deprivation quintile.

Shops located within the school fringe were visited, each shop within a radius of ten minutes' walking distance. A stopwatch was used to estimate the walking distance of each shop selling novelty sweets from the chosen schools. The school fringe was determined as the area in close proximity to schools according to the definition provided by Sinclair and Winkler ${ }^{27}$ 'where children can buy items while walking to and from school and during lunch time'.

Shops around the schools were visited just before children left school at the end of the school day (14:00-15:00 hrs); for the other retail outlets visits were conducted during weekdays. At all visits novelty sweets available for sale were noted. In addition, the retail prices and the location of display were recorded with regard to the height of the shelves and the proximity to the check out. Post visit an assessment was made of the difference in availability of novelty sweets in relation to deprivation. Ethical approval for this study was granted by the Dental School Research Ethics Committee (DSREC reference 15/41a).

Data was analysed using SPSS v20 (IBM Corporation, Chicago, USA). Analysis of data included descriptive statistics, incorporating frequency distributions and cross tabulations. MapInfo v10 (Pitney Bowes, New York, USA) was used to represent WIMD, store and school location data. 


\section{RESULTS}

A total of 68 stores were visited; 19 of these stores sold at least one novelty sweet type. In total 84 novelty sweets were identified, but this included repeats. However, 38 unique novelty sweet varieties were available in the 19 stores (Table 1). School 3, in the most deprived area, had the largest percentage of shops selling novelty sweets; this was also apparent within the city centre, where at each location 50\%, five out of ten shops sold them (Table 1). In addition more varieties of novelty sweets were sold around these two locations, 16 varieties in close proximity to school 3 and 17 varieties within the selected city centre shops. Furthermore school 2 in the least deprived area had no shops around the school fringe selling novelty sweets (out of the 11 visited), as was the case for school 5 which bordered the second least deprived area out of ten shops visited (Table 1). Both schools 1 and 4 which were in the second most and middle deprived areas of Cardiff respectively had 33\% (4/12) of shops selling novelty sweets. The shops surrounding school 1 stocked 15 varieties of different novelty sweets, compared with 11 types in shops close to school 4. Only one of the three visited supermarkets sold novelty sweets; however this was the only supermarket situated within a school fringe of school 4, in the middle deprived area of the city, which stocked five types of novelty sweets (Table 1).

A frequency distribution of the prevalence of the novelty sweets is presented in Figure 2; the most frequently available sweet variety was Brain Licker, available in eight separate shops. At the other end of the distribution there were 18 unique sweet varieties, including Alien Liquid Candy, Lick the Teeth, Snot Shots and Sour Shocks Chew, which were each available in one shop only.

A visual representation of the ten most available novelty sweets in the Cardiff area is presented in Figure 3 and these were (in descending order):

- Brain Licker

- Push Pop

- Juicy Drop

- Lickedy Lips

- Big Baby Pop

- Vimto candy spray

- Toxic Waste

- Tango candy spray

- Brain Blasterz Bitz

- Mega Mouth candy spray.

The average price of the 38 unique novelty sweet varieties was £0.96 with a range from £0.10 (for Sour Shocks Chew) to £2.99 (for Candy Blood). Thirty-two of the 84 sweet types were priced at $£ 1.00$ (Fig. 4). In

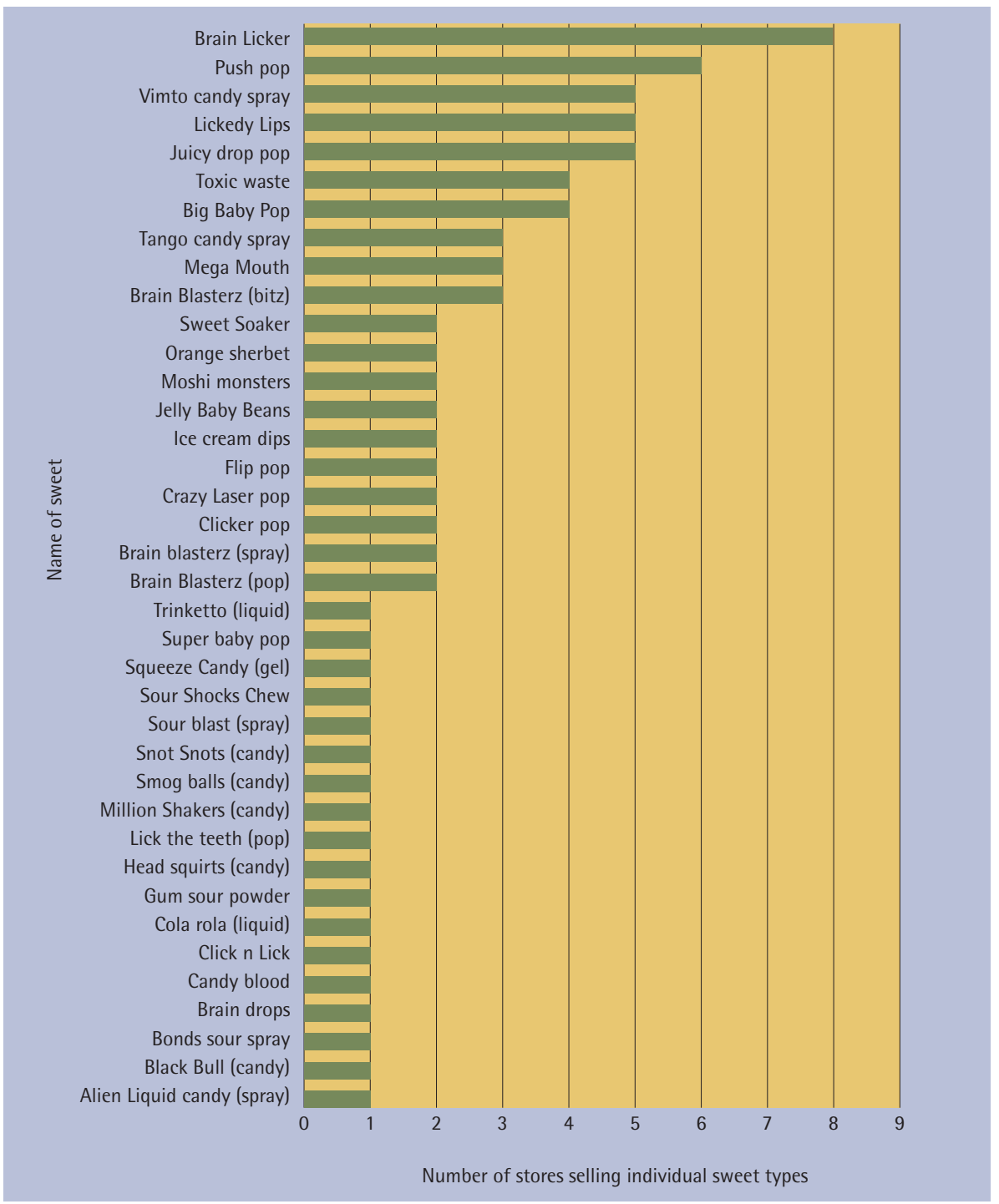

Fig. 2 Prevalence in 21 stores, out of the 70 visited, stocking one or more novelty sweets

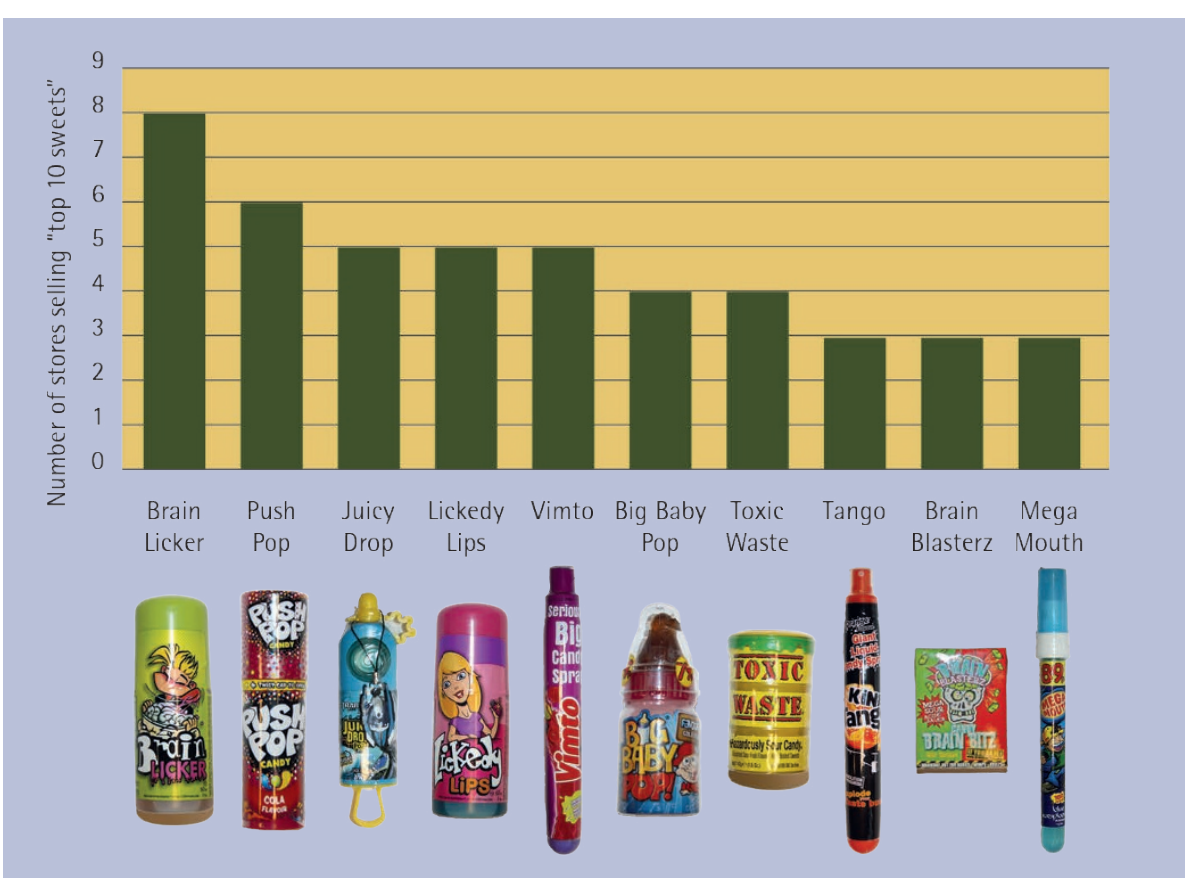

Fig. 3 Availability of novelty sweets, for the ten most frequently identified types across 19 Cardiff stores 


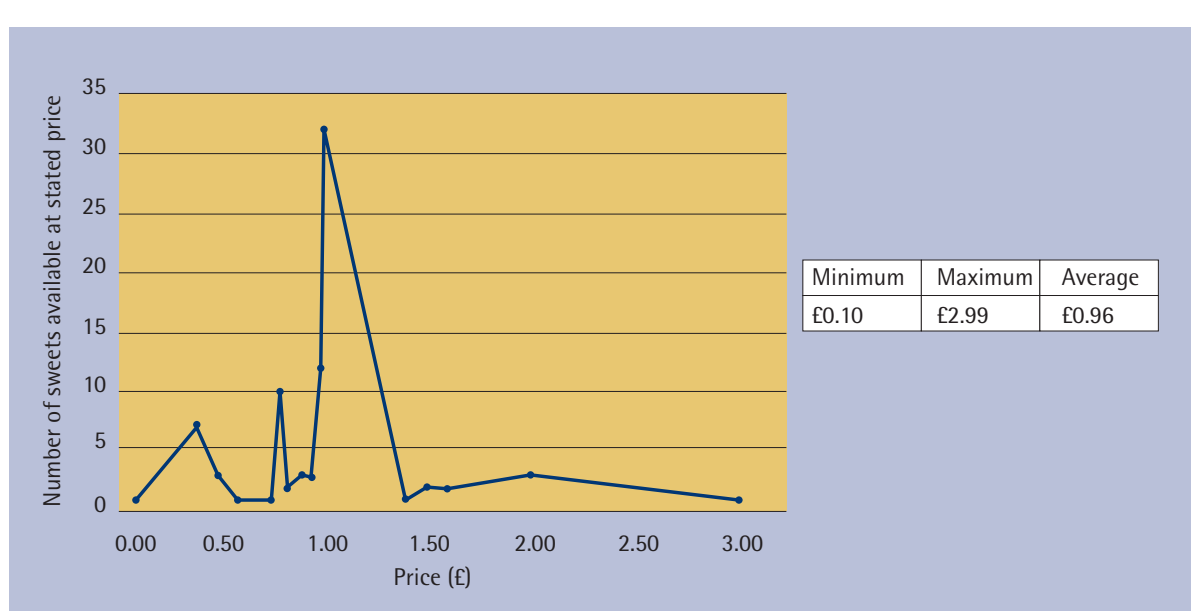

Fig. 4 Price distribution of all 84 novelty sweets (including repeats)

addition, the novelty sweets were displayed on low shelves (under $136 \mathrm{~cm}$ ) in $74 \%$ (14 out of 19) of the shops, which means that they were accessible to all age groups. Furthermore in 37\% (7 of 19) of the shops, novelty sweets were displayed in the checkout area (the remainder were displayed in dedicated confectionery aisles).

The novelty sweets were categorised into seven main types reflecting their textural properties, that is, gels, sprays, liquids and hard candy. The most available product formulations were solid lollipops (for example, Baby Pop), liquid spray (for example, Vimto candy spray), liquids (for example, Brain Licker) and solid candy (for example, Toxic Waste, Table 2).

\section{DISCUSSION}

From the results of the present study, the most popular novelty sweets identified in the Cardiff area were (in descending order) Brain Licker, Push Pop, Juicy Drop Pop, Lickedy Lips, Big Baby Pop, Vimto candy spray, Toxic Waste, Tango candy spray, Brain Blasterz Bitz and Mega Mouth candy spray. Previous studies in the $\mathrm{UK}^{24,25}$ and the Netherlands ${ }^{26}$ investigating novelty sweets also reported on Brain Licker, Juicy Drop Pop, Big Baby Pop and Mega Mouth. The prevalence of novelty sweets as part of the larger sour candy market is also noted by authors in the USA. ${ }^{29}$ The continuing presence of these products indicates good market penetration. The results of the present study showed the availability of a wider range of novelty sweets than previously which may be explained by the recent expansion of this confectionery range in the UK. ${ }^{20}$ For example, Lickedy Lips is a version of Brain Licker which was not included in the previous studies. ${ }^{24-26}$ Lickedy Lips appears to be marketed towards girls, in terms of its packaging (a lipstick holder) and colour (pink). The quantification and ranking of the novelty sweets identified in this research could provide a focus for future studies.

Notably, it was found that some stores ( $n=6$ ) with multiple outlets sell novelty sweets only in shops in close proximity to schools. These results support the view that targeted marketing of these sweets is being used as a strategy by these stores. ${ }^{27}$

It was also observed in the present study that the availability of novelty sweets was greater in the most deprived areas. The increased availability of sweets in deprived areas may be because they are a palatable low cost source of energy. This result supports previous findings in the USA and the UK. ${ }^{27,30,31}$

The price of the available types of novelty sweets in the visited shops was in the range of $£ 0.10-£ 2.99$, while the price range of the most common novelty sweets was in the range of $£ 0.39-£ 1.00$ with an average price of £0.96. This range of prices is likely to be affordable to children in the UK where the average weekly pocket money for children was reported as £6.20 in 2013. ${ }^{22}$ Children could therefore buy several novelty sweets each week, with potential effects on the general and oral health of children., ${ }^{7,819}$ It has been reported that only one in four children in the UK looks for healthy choices in food when shopping. ${ }^{32}$

Novelty sweets were displayed on relatively low shelves and the checkout area, at heights accessible to UK children. This confirms that physical engagement is widely used by retailers in child-targeted marketing. ${ }^{27}$

\section{CONCLUSION}

A wide range of novelty sweets was available to high school children in the Cardiff area. There appeared to be a relationship between the level of deprivation and the availability of novelty sweets. Furthermore the prices of this type of confectionery were

\begin{tabular}{l|l|l}
\hline \multicolumn{2}{|c|}{ Table 2 Sweets categorised by form } \\
Consistency & Form of sweet & $\begin{array}{l}\text { Number } \\
\text { (including } \\
\text { repeats) }\end{array}$ \\
\hline Liquid & Liquid & 17 \\
\hline Liquid & Spray & 18 \\
\hline Gel & Gel & 1 \\
\hline Solid & Candy & 17 \\
\hline Solid & Lollipop & 22 \\
\hline Solid & Lollipop \& powder & 6 \\
\hline Solid & Powder & 3 \\
\hline Total & & 84
\end{tabular}

well within the reported pocket money range available to children.

The recent lobby by Public Health England $^{33}$ and others for a sugar tax on sugar sweetened beverages (SSBs) was successful in March 2016. ${ }^{34}$ Limiting the consumption of SSBs should help reduce the overall contribution of free sugars to the national diet but consideration also needs to be awarded to others foods high in sugar, including confectionery, in order to bring about the 5\% of total energy goal. ${ }^{14}$

A more holistic approach to change could draw upon the UK national salt reduction campaign. This was coordinated by the UK Food Standards Agency and involved a consumer education programme relating to salt consumption and voluntary salt reduction targets for the food industry. These have achieved significant reductions in salt intakes over the last ten years. ${ }^{35,36}$

The study confirms that novelty sweets are widely available, both in terms of location and cost, to children in Cardiff. It also confirms that this is an expanding market in terms of product diversification and market penetration. Those personnel involved in delivering dental and wider health education or health promotion need to be aware of current trends in children's confectionery. Therefore, the effects of novelty sweets on the general and dental health of children should be further investigated.

1. Arnadottir I B, Holbrook W P, Eggertsson $\mathrm{H}$ et al. Prevalence of dental erosion in children: a national survey. Community Dent Oral Epidemiol 2010; 38: 521-526.

2. Health \& Social Care Information Centre. Child Dental Health Survey 2013, England, Wales and Northern Ireland [NS]. 19 March 2015. Available at: https://www.gov.uk/government/statistics/ childrens-dental-health-survey-2013 (accessed 19 May 2016).

3. Cancer Research UK. Overweight and Obesity by Sex and UK Region: Children. 2011. Online information available at: http://www.cancerresearchuk. org/health-professional/cancer-statistics/risk/ childhood-overweight-and-obesity\#heading-One (Accessed May 2016). 
4. Moynihan PJ. The role of diet and nutrition in the aetiology and prevention of oral diseases. Bull World Health Organ 2005; 83: 694-699.

5. Fung A, Brearley Messer L. Tooth wear and associated risk factors in a sample of Australian primary school children. Aust Dent J 2013; 58: 235-245.

6. Dugmore C R, Rock WP. A multifactorial analysis of factors associated with dental erosion. Br Dent J 2004; 196: 283-286; discussion 73

7. Burt B A, Pai S. Sugar consumption and caries risk: a systematic review. J Dent Educ 2001; 65: 1017-1023.

8. Bartlett D W, Fares J, Shirodaria S, Chiu K, Ahmad $N$, Sherriff M. The association of tooth wear, diet and dietary habits in adults aged $18-30$ years old. $J$ Dent 2011; 39: 811-816.

9. Malik V S, Schulze M B, Hu F B. Intake of sugar-sweetened beverages and weight gain: a systematic review. Am J Clin Nutr 2006; 84: 274-288.

10. Hu F B, Malik V S. Sugar-sweetened beverages and risk of obesity and type 2 diabetes: epidemiologic evidence. Physiol Behav 2010; 100: 47-54

11. Ludwig D S, Peterson K E, Gortmaker S L. Relation between consumption of sugar-sweetened drinks and childhood obesity: a prospective, observationa analysis. Lancet 2001; 357: 505-508.

12. Ruxton $\mathrm{CH}$, Gardner $\mathrm{E} J$, McNnulty H M. Is sugar consumption detrimental to health? A review of the evidence 1995-2006. Crit Rev Food Sci Nutr 2010; 50: 1-19.

13. Harris R, Nicoll A D, Adair P M, Pine C M. Risk factors for dental caries in young children: a systematic review of the literature. Community Dent Health 2004; 21(1 Suppl): 71-85.

14. Scientific Advisory Committee on Nutrition. SACN Carbohydrates and Health Report. 2015. Available at: https://www.gov.uk/government/publications/ sacn-carbohydrates-and-health-report (accessed 19 May 2016).

15. Moynihan P J, Kelly S A. Effect on caries of restricting sugars intake: systematic review to inform WHO guidelines. J Dent Res 2014; 93: 8-18.

16. British Nutrition Foundation. 2014. Exploring sugars in the foods we buy, Frequently Asked
Questions. Available at: https://www.nutrition. org.uk/attachments/article/882/Exploring\%20 sugars\%20FA0.pdf (accessed 19 May 2016).

17. Al-Majed I, Maguire A, Murray J J. Risk factors for dental erosion in 5-6 year old and 12-14 year old boys in Saudi Arabia. Community Dent Oral Epidemiol 2002; 30: 38-46.

18. Scientific Advisory Committee on Nutrition. Carbohydrates and Health report. 2015. Online information available at: https://www.gov.uk/government/ uploads/system/uploads/attachment_data/ file/445503/SACN_Carbohydrates_and_Health.pdf (Accessed May 2016).

19. Te Morenga L, Mallard S, Mann J. Dietary sugars and body weight: systematic review and meta-analyses of randomised controlled trials and cohort studies. BMJ 2013; 346: e7492.

20. Mintel. Sugar Confectionery UK. 2012. Available at: http://www.sweetretailing.co.uk/indexphp/confectionery_advice/view/uk_confectionery_market_update_mintel_2012 (accessed 19 May 2016).

21. Stewart $K F$, Fairchild $R$ M, Jones $R J$, Hunter $L$, Harris C, Morgan M Z. Children's understandings and motivations surrounding novelty sweets: a qualitative study. Int J Paediatr Dent 2013; 23: 424-434.

22. Lloyds Banking Group-Halifax. Parents loosen purse strings as Pocket Money increases. 2013. Available at http://www.lloydsbankinggroup.com/ media/press-releases/2013-press-releases/halifax/ parents-loosen-purse-strings-as-pocket-moneyincreases/ (accessed 19 May 2016)

23. Social Branding. Social brands 100 in FMCG ranking. 2015. Online information available at: http:// www.socialbrands100.com/uploads/rankings/ reports/HSBD1041_SB100_whitepaper_FMCG_ v5.pdf (Accessed May 2016).

24. Davies R, Hunter L, Loyn T, Rees J. Sour sweets: 204: E3; discussion 84-85.

25. Beeley J A. Novelty sweets: a new cause of erosion? British Society for Dental Research Annual Scientific Meeting 2005.
26. Gambon D L B, Nieuw H S, Amerongen A V. The erosive potential of candy sprays. Br Dent J 2009; 206: E20; discussion 530-531.

27 Sinclair S, Winkler T. The School Fringe, From Research to Action. Nutrition Policy Unit, London Metropolitan University. 2009. Online information available at: http://www.fhf.org.uk/meetings/2008-07-08_ School_Fringe.pdf (Accessed May 2016).

28. Welsh Goverment. 2011. Welsh Index of Multiple Deprivation. Available at: http://wales.gov.uk/ topics/statistics/theme/wimd/wimd2011/?lang=en (accessed October 2015).

29. Robyn R L, Robert J M, John D R. Pucker up: the effects of sour candy on your patients' oral health. A review of the dental erosion literature and $\mathrm{pH}$ values for popular candies. Northwest Dent 2008; 87: 20-21.

30. Chiu S H, Dimarco M A, Prokop J L. Childhood obesity and dental caries in homeless Children. J Pediatr Health Care 2013; 27: 278-283.

31. Drewnowski $A$. The economics of food choice behaviour: why poverty and obesity Are Linked. Nestlé Nutr Inst Workshop Ser 2012; 73: 95-112.

32. Mintel. Children's Eating and Drinking Habits UK. 2011. Online information available at: http://store mintel.com/childrens-eating-and-drinking-habits-uk-february-2011 (Accessed May 2016).

33. Public Health England. Sugar reduction: the evidence for action. 2015. Available at: https://www.gov. uk/government/uploads/system/uploads/attachment_data/file/470179/Sugar_reduction_The_evidence_for_action.pdf (accessed April 2016).

34. UK Parliament. Sugar: Taxation. 2016. Online information available at: https://www.parliament. uk/business/publications/written-questions-answers-statements/written-question/Lords/201603-17/HL7177/ (Accessed 24 May 2016).

35. Wyness L A, Butriss J L, Stanner S A. Reducing the population's sodium intake: the UK Food Standards Agency's salt reduction programme. Public Health Nutr 2012; 15: 254-261.

36. Consensus. Food industry progress. 2014. Available at: http://www.actiononsalt.org.uk/news/industry/31988.html (accessed 19 May 2016)

This work is licensed under a Creative Commons Attribution 4.0 International License. The images or other third party material in this article are included in the article's Creative Commons license, unless indicated otherwise in the credit line; if the material is not included under the Creative Commons license, users will need to obtain permission from the license holder to reproduce the material. To view a copy of this license, visit http://creativecommons.org/licenses/by/4.0/ (c) The Author(s) 2016 